\title{
Financial intermediation as a source of aggregate instability
}

\author{
Fabrizio Mattesini \\ Università di Roma "Tor Vergata" \\ Via Columbia 2, 00133 Rome, Italy \\ mattesini@economia.uniroma2.it
}

July 2005

\begin{abstract}
We consider a simple overlapping generations economy where the behavior of intermediaries, in a market characterized by asymmetric information and moral hazard, may give rise to cyclical equilibria. When capital increases output and savings also increase, and therefore more capital will be available in the following period. At the same time, however, interest rates also decrease and this induces intermediaries to reduce the amount of resources devoted to monitoring. A larger number of firms will select low quality projects and, because of this, less capital will be produced in the following period. For some parameter values this second effect may prevail over the first one and the stock of capital in period $t+1$ may actually be lower than the stock of capital in period t. The model provides a rigorous interpretation of the view associated with Hyman Minsky [14], Charles Kindleberger[12], and Henry Kaufman[11], according to which expansions come to an inevitable end because of excessive or ill-considered lending that took place during the boom.
\end{abstract}

\section{Introduction}

There is a view of the business cycle, associated with Hyman Minsky [14], Charles Kindleberger[12], and Henry Kaufman[11], according to 
which expansions come to an inevitable end because of excessive or ill-considered lending that took place during the boom. When the economy grows, it is asserted, financial intermediaries are usually able to collect a large number of funds at low cost but, as the expansionary phase continues, they become less and less careful and allow firms to invest in lower quality projects. When the effects of these projects become evident, there is a fall in the level of economic activity and a recession ensues.

The aim of this paper is to provide a rigorous interpretation of this view by presenting a model in which financial intermediation may be a source of instability for the aggregate economy. Differently from the theories of Minsky, Kindleberger and Kaufman, the model does not rely on the hypothesis of irrational behavior of banks, but rather interprets cycles as the effect of asymmetric information in the credit market. We use a standard OLG framework where capital producing firms need to borrow from intermediaries which, in turn, face a moral hazard problem.

In this paper, intermediaries have the possibility to impede firms from undertaking inefficient investment projects by monitoring them, but monitoring is costly and the amount of resources devoted to monitoring depends on interest rates. The higher are interest rates, the higher the monitoring effort of intermediaries. An increase in the stock of capital in period t may produce two conflicting effects on the stock of capital in period $t+1$. The first one is positive and is simply due to the fact that when capital increases, output and savings also increase and therefore more capital will be available in the following period. The second effect, instead, is negative. As capital and output increase, there is a fall in interest rates and this induces intermediaries to decrease their monitoring activity. As a consequence, a larger number of firms will select low quality projects and less capital will be produced in the following period. For some parameter values this second effect may turn out to be more important than the first one and therefore, following an increase in the stock of capital at period t, the stock of capital in period $t+1$ may actually be lower and cycles may appear.

This model is not the first to show that complex dynamics may arise in OLG environments. Differently from the existing literature, 
however, it does not rely on implausible hypotheses on preferences and technology but rather describes a mechanism that has intuitive appeal and is consistent with the conventional wisdom of participants and observers of financial markets. The recent debate on the East Asian crisis of 1997, for example, has produced some interesting evidence that the mechanism we describe in this paper may have played an important role in causing the sharp contraction of these economies that, in turn, gave rise to the currency crisis.

As is well documented by Corsetti, Pesenti and Roubini, ([6]) these countries had already experienced, at the onset of the crisis, a sharp deterioration of macroeconomic conditions which was then amplified by the subsequent currency crisis. In all the countries involved, the recession came at the end of a period of GDP growth averaging around $7 \%,{ }^{1}$ and high investment. In the period $1990-97$ the investment-GDP ratio was above $30 \%$ in all countries and $20-25 \%$ in the Philippines and Taiwan. These high rates of investment were fueled by a lending boom ${ }^{2}$ during which, as we describe in this model, the availability and low cost of credit led intermediaries to finance lower quality investments. By the end of the expansionary phase many banks were experiencing high rates of nonperforming loans and widespread bankruptcies ${ }^{3}$. At the same time, as documented by several papers such as Harvey and Roper ([10]), Claessens ([?]) and Pomerleano ([16]) in the years preceding the crisis there was a significant decline in the profitability of the East Asian economies.

Consistently with our model, therefore, the economic contraction that led to the currency crisis was preceded by an economic boom that stimulated excessive lending by intermediaries which started financing low or negative present value investments. As these investments did indeed prove to be unsound, there was a halt in the process of growth, and a downturn in economic activity.

\footnotetext{
${ }^{1}$ The only exception was the Philippines, where growth rates were low in the 1990s but were around $5 \%$ after 1994 .

${ }^{2}$ The private credit to GDP ratio was strongest in the Philippines (151\%), Thailand $(58 \%)$ and Malaysia (31\%) and more modest, but still relevant, in Korea, Singapore and Hong Kong (15\%).

${ }^{3}$ As documented by Corsetti, Pesenti and Roubini,([6]), for example, in the years before 1997 a large number of Korean industrial conglomerates (chaebols) filed for bankruptcy.
} 
This paper represents a significant departure from the most recent literature developed by Bernanke and Gertler [3], Greenwald and Stiglitz [9], Kyotaki and Moore [13], Calmstrom and Fuerst [5] and Bernanke, Gertler and Gilchrist [4]. While these papers show that, because of asymmetric information in the credit market, small shocks may be amplified, transforming minor slow-downs in the level of economic activity into major recessions, in our model the behavior of intermediaries is actually the cause of cyclical instability. In this respect our model takes a view similar to the one proposed by Azariadis and Smith ([1]) which analyzes an OLG economy characterized by adverse selection in the credit market, and Aghion, Bacchetta and Banerjee $([2])^{4}$ which instead analyzes cycles in small open economy. In the Azariadis and Smith paper the economy can follow either a full information equilibrium or a credit rationing equilibrium and output fluctuations are due to the economy switching between the two regimes, depending on depositors expectations. In the model proposed by Aghion, Bacchetta and Banerjee, aggregate fluctuations are instead determined by endogenous fluctuations in the price of a country specific input combined with a corporate balance sheet effect. The model we present in this paper is, to our knowledge, the first one to relate the possibility of endogenous cycles to the behavior of intermediaries and to their tendency to finance relatively riskier investments during periods of boom.

In Section 2 we describe the model, in Section 3 we study optimal contracts between intermediaries and firms under asymmetric information and in Section 4 we study the dynamics of the model.

\section{The model}

We consider a discrete time economy populated by an infinite sequence of two period lived overlapping generations. At each date a continuum of young agents is born with a unit mass. At each time $t$ a single final good is produced using a simple Cobb-Douglas technology. Output $Y_{t}$ is given by $Y_{t}=A_{t} K_{t}^{\alpha} L_{t}^{1-\alpha}$ where $K_{t}$ is capital, $L_{t}$

\footnotetext{
${ }^{4}$ Suarez and Sussman [18] in the context a highly stylized Stiglitz and Weiss economy, also propose a model in which credit market imperfections give rise to endogenous cycles.
} 
is labor, and $A_{t}$ is a scale parameter indicating the stock of knowledge in the economy. Denoting by $k_{t}$ the capital-labor ratio and by $y_{t}$ the output-labor ratio we can rewrite the production function in intensive form so that $y_{t}=A_{t} k_{t}^{\alpha}$. We assume, as in Romer $([17]),{ }^{5}$

$$
A_{t}=k_{t}^{\eta}, \quad \alpha+\eta=1
$$

which implies that the stock of knowledge depends on the stock of capital per person in the economy, so that aggregate capital gives rise to production externalities. We also assume that capital depreciates completely during production in each period.

Perfect competition in the final good sector implies that the price of the input $k_{t}, \rho_{t}$ and the wage rate $w_{t}$ (both measured in terms of the good $y_{t}$ ), given (A1), are

$$
\begin{gathered}
\rho_{t}=A_{t} \alpha k_{t}^{\alpha-1}=\alpha \\
w_{t}=A_{t} k_{t}^{\alpha}-A_{t} \alpha k_{t}^{\alpha-1} k_{t} \equiv(1-\alpha) k_{t}
\end{gathered}
$$

Equations (2.2) and (2.1) imply zero profits for all firms producing $y_{t}$.

Young agents are divided into two types: "borrowers" and " lenders". Borrowers have access to a set of stochastic technologies for converting the time $t$ final good into time $t+1$ capital, but are endowed with no labor. Lenders have no access to these technologies but are endowed with a unit of labor which is supplied inelastically and use their wage income to fund young and old period consumption. We denote by $\omega$ the fraction of borrowers in the economy and by $1-\omega$ the fraction of lenders.

Lenders at time $t$ choose the level of young age consumption $c_{1 t}$ and old age consumption $c_{2 t+1}$ to maximize a utility function $u\left(c_{1 t}, c_{2 t+1}\right)$. We assume

\footnotetext{
${ }^{5}$ As we will see later on this assumption is analytically very convenient, because it implies that the price of the input $k_{t}$ remains always constant and independent on the level of $k_{t}$.
} 


$$
u\left(c_{1 t}, c_{2 t+1}\right)=\ln c_{1 t}+\ln c_{2 t+1} .
$$

At the end of the first period of their lives lenders can either store their savings, earning a gross return $r_{t+1}=1$, or deposit their savings with intermediaries, earning a gross return $r_{t+1} \geq 1$. Denoting savings by $s_{t}$, lenders maximize utility under the budget constraints $c_{1 t}=w_{t}-s_{t}, c_{2 t+1}=r_{t+1} s_{t}$, and from the first order conditions we obtain

$$
s_{t}\left(w_{t}\right)=\frac{w_{t}}{2}=\frac{(1-\alpha) k_{t}}{2} .
$$

Borrowers consume only in the second period of their lives and maximize the expected value of consumption $E\left(c_{t+1}^{b}\right)$. Each borrower has access to two possible investment projects: a good project and a bad project. The good project transforms $y_{t}>0$ units of the final good invested at time $t$ into $a y_{t}^{\beta}$ units of capital at time $t+1$. The bad project transforms $y_{t}>0$ units of the final good invested at $t$ into $a y_{t}^{\beta}$ units of capital at time $t+1$ with probability $p$ and 0 with probability $1-p$. Moreover, the bad project also allows the entrepreneur to obtain a private benefit $B$ which consists of an amount of the good that entrepreneurs can directly consume. This private benefit represents a diversion of resources from the production of capital to the enterpreneur's personal use that cannot be impeded. This means that if the entrepreneur borrows to finance its investment, the lender cannot reach the private benefit, even if the borrower defaults on its loan.

We assume

$$
B>\alpha a(\alpha a \beta)^{\frac{\beta}{1-\beta}}-(\alpha a \beta)^{\frac{1}{1-\beta}}
$$

which implies that the private benefit is always very high for an entrepreneur that chooses the bad technology. 


\section{Financial Intermediation}

Since they are not endowed with any initial level of the final good, borrowers seek to finance investment projects by borrowing in the market. At the beginning of time $t$ capital producing firms borrow an amount $y_{t}$ from lenders and undertake production. At time $t+1$ they sell the capital produced in the previous period to the firms producing the good and they repay the principal and the interest on the loan. The loan contract signed at time t establishes the size of the loan and the repayment $x_{t+1} y_{t}$ due to lenders. If the firm undertakes the good project in time $t$ it will expect a profit $\rho_{t+1} a y_{t}^{\beta}-x_{t+1} y_{t}$ in time $t+1$. If the firm undertakes the bad project in time $t$ it will expect a profit $p\left(\rho_{t+1} a y_{t}^{\beta}-x_{t+1} y_{t}\right)$ in time $t+1$ plus the private benefit $B$. If the credit market is characterized by asymmetric information, i.e. if a lender cannot directly observe the type of project chosen by a borrower, a moral hazard problem appears, since the borrower will not always choose the good technology, but will choose it only if it gives higher expected profits, i.e. only if

$$
\rho_{t+1} a y_{t}^{\beta}-x_{t+1} y_{t} \geq p\left(\rho_{t+1} a y_{t}^{\beta}-x_{t+1} y_{t}\right)+B .
$$

We can now prove:

Lemma 1 If assumption (A3) and equation (2.1) are satisfied, there exists no level of $y_{t}$, for any possible $x_{t+1}$, that satisfies equation (3.1).

In this context, the only way to minimize the consequences of asymmetric information in the credit market is to engage in costly monitoring. We assume in this paper that individual lenders cannot observe borrowers, but that there exists a discrete subset of lenders that are endowed with a monitoring technology. These agents, which we call intermediaries, specialize in lending to capital producers and invest resources in monitoring them. In the real world, monitoring means a series of activities like the inspection of firms' predicted 
cash flow, their balance sheet position, their management etc.. Often monitoring means verifying that a firm respects the many covenants that are usually included in financial contracts to induce diligent behavior by borrowers. With this in mind we interpret monitoring as a series of activities aimed at preventing firms from using the bad technology.

In this model we allow for the possibility that the monitoring activity of intermediaries is not succesful, i.e. we assume that when an intermediary invests an amount $e_{t} y_{t}$ in monitoring a firm there is a probability $\pi\left(e_{t}\right) \in[0,1]$ that a firm undertakes the good project. We assume $\pi(0)=0, \pi^{\prime}\left(e_{t}\right)>0$ and $\pi^{\prime \prime}\left(e_{t}\right)<0$. The probability that monitoring succeeds in inducing firms to use the good technology is an increasing function of the amount of resouces, expressed as a proportion of the size of the loan, invested in monitoring entrepreneurs. Monitoring howerver is subject to decreasing marginal returns. The idea is that collecting information is relatively easy at the beginning but the, when the monitoring effort becomes greater, there is always some residual information that can be obtained only by incurring into larger and larger expenses. ${ }^{6}$ In order to obtain explicit solutions that will easily simplify the study of the dynamics of our model, we assume ${ }^{7}$

$$
\pi\left(e_{t}\right)=e_{t}^{\frac{1}{2}} \quad \text { and } \quad \pi\left(e_{t}\right)=1 \text { for } e_{t}>1
$$

The sequence of events is the following. Intermediaries collect deposits and lend to capital producing firms. After receiving a loan, the firm selects a project. As a matter of fact, given lemma 1, all firms opt for the bad project. Then banks monitor all firms. If

\footnotetext{
${ }^{6}$ In this paper intermediaries will choose the optimal amount of resources devoted to monitoring by equating the marginal benefit of monitoring to the marginal cost. The convexity of the function $\pi\left(e_{t}\right)$ allows us to obtain an interior solution, i.e. it allows for the possibility that the fraction of firms undertaking, in equilibrium, the bad project is less than one.

${ }^{7}$ In order to obtain complex non linear dynamics in this model it is sufficient to assume that $\pi_{t}$ is an increasing and concave function of $s_{t}$. As we will see later on, assumption (A4) allows us to characterize the possible dyanamic solutions of our model in a simple and intuitive way.
} 
monitoring is successful, the firms found to choose the bad project are forced to return to the good project without any penalty. In this case, firms will repay the amount $x_{t+1}$ with certainty. If monitoring is not successful, the borrower will choose the bad project and will default on the loan with probability $p$. Since there is a discrete number of intermediaries and a continuum of borrowers, each intermediary will lend to a large number of borrowers and therefore $p$ not only represents the probability that a borrower that chooses a bad technology defaults, but also the number of borrowers that go bankrupt. Analogously, $\pi\left(e_{t}\right)$ not only represents the probability that a firm undertakes the good project, but also the number of firms that undertake the good project. On the other side, although the number of intermediaries is discrete and therefore small relative to the number of borrowers, we consider a situation in which their number is large enough to imply perfect competition and free entry in the intermediation business. Intermediaries therefore will earn zero profits on their lending activity.

Given the structure of the game, we can distinguish between two separate stages. In the first stage, agents agree on a contract that specifies the size of the loan $y_{t}$ and the payment $x_{t+1}$ to the lender, on the basis of their expectations about the behavior of intermediaries. In the second stage intermediaries select the optimal amount of resources to employ in the monitoring activity. Notice that, given assumption (A4) choosing $e_{t}$ is equivalent to choosing the probability $\pi_{t}$ and therefore we can use this last variable as the relevant choice variable. Assuming that agents are perfectly informed and considering that, given (A4), $e_{t}=\pi_{t}^{2}$, the optimal contract can be found using backward induction, by first determining the probability that a firm chooses the good technology, which crucially depends on the amount of the good invested in monitoring, and then by studying the optimal contract, conditional on such probability.

Let us first consider the problem of an intermediary that, given a contract $\left(x_{t+1}, y_{t}\right)$, chooses the level of $\pi_{t}$ that solves

Problem 1 - stage 2

$$
\max \quad x_{t+1} y_{t} \pi_{t}+x_{t+1} y_{t}\left(1-\pi_{t}\right) p-\pi_{t}^{2} y_{t}-r_{t+1} y_{t}
$$


subject to

$$
\begin{aligned}
& \pi_{t} \leq 1 \\
& \pi_{t} \geq 0 .
\end{aligned}
$$

The first order conditions imply

$$
\begin{gathered}
x_{t+1}(1-p)=2 \pi_{t} \Leftrightarrow 0<\pi_{t}<1 \\
x_{t+1}(1-p)>2 \pi_{t} \Leftrightarrow \pi_{t}=1 \\
x_{t+1}(1-p)<2 \pi_{t} \Leftrightarrow \pi_{t}=0
\end{gathered}
$$

Given these solutions to the intermediaries' optimization problem, the optimal contract between a borrower and a lender is given by the pair $\left(x_{t+1}, y_{t}\right)$ that solves

Problem 1 - stage 1

$$
\max \left[\left(\pi_{t}+p\left(1-\pi_{t}\right)\right] \alpha a_{t} y_{t}^{\beta}+B\left(1-\pi_{t}\right)-\left[x_{t+1} \pi_{t}+x_{t+1} p\left(1-\pi_{t}\right)\right] y_{t}\right.
$$

subject to

$$
x_{t+1} \pi_{t}+x_{t+1} p\left(1-\pi_{t}\right)-\pi_{t}^{2}-r_{t+1}=0
$$




$$
x_{t+1}(1-p)=2 \pi_{t} \text { if } 0<\pi_{t}<1
$$

$$
x_{t+1}(1-p)>2 \pi_{t} \text { if } \pi_{t}=1
$$

$$
x_{t+1}(1-p)<2 \pi_{t} \text { if } \pi_{t}=0
$$

$\left[\left(\pi_{t}+p\left(1-\pi_{t}\right)\right] \rho_{t+1} a y_{t}^{\beta}+B\left(1-\pi_{t}\right)-\left[x_{t+1} \pi_{t}+x_{t+1} p\left(1-\pi_{t}\right)\right] y_{t} \geq 0\right.$

Equation (3.6) is the zero profit constraint, equations (3.7) , (3.8) and (3.10) define the probability that a firm is monitored and (3.10) is the participation constraint. We can now prove:

Lemma 2 The solution to problem 1 implies:

$$
\begin{gathered}
x_{t+1}=\frac{a \alpha \beta}{y_{t}^{1-\beta}} \text { if } x_{t+1} \geq 2 \\
\pi_{t}=\frac{(1-p) \alpha a \beta}{2 y_{t}^{1-\beta}} \text { if } 2>x_{t+1} .
\end{gathered}
$$

Lemma 2 gives us a crucial result of this paper, as it establishes a negative relationship between the amount of resources devoted to monitoring, which results in a higher probability that firm undertakes the good project, and the amount of the good utilized in the production of capital. From equation (3.2) we see that, when the optimal level of monitoring implies that only a fraction of the firms choose the good project, there exists a positive relationship between the loan interest rate and the number of firms that use the good 
technology. The expected return an intermediary obtains from increasing the monitoring effort, in fact, is given by the interest factor he expects when the firm chooses the good technology $x_{t+1}$ minus the interest factor he expects when firms choose the bad technology $x_{t+1} p$. When the interest rate increases, the expected marginal return from monitoring increases and firms increase the amount of resources devoted to monitoring up to the point in which the marginal cost is equal to the expected marginal benefit. The negative relationship between $\pi_{t}$ and $y_{t}$ derives from the fact that the higher is the loan interest rate, the lower is the demand for credit by firms. When the amount of the good demanded by capital producing firms is low, the loan interest rate is high and therefore, given the relationship between interest rates and the volume of monitoring, intermediaries increase their monitoring effort which translates in a larger number of firms undertaking the good technology.

\section{General equilibrium and dynamics}

Since agents save by depositing their funds with intermediaries, the supply of loanable funds is given by the level of savings in the economy $(1-\omega) s_{t}=\frac{(1-\omega) w_{t}}{2}=\frac{(1-\omega)(1-\alpha) k_{t}}{2}$. Defining $\Phi=\frac{(1-\omega)(1-\alpha)}{2 \omega}$, equilibrium in the market for loanable funds, illustrated in figure 1 , is given by

$$
y_{t}=\Phi k_{t}
$$

The level of $k_{t}$ at which intermediaries switch from a full monitoring regime where $\pi_{t}=1$ to a partial monitoring regime where $\pi_{t}<1$ is obtained by setting $x_{t+1}=2$ and is given by $^{8}$

$$
\widehat{k}=\frac{1}{\Phi}\left(\frac{\alpha \beta}{2}\right)^{\frac{1}{1-\beta}} \text {. }
$$

${ }^{8}$ Notice that the same result can be obtained by setting $n_{t}=1$ in equation (3.12). 
When $k_{t} \leq \widehat{k}, \pi_{t}=1$ and all firms use the good technology to produce next period's capital. Therefore,

$$
k_{t+1}=\omega a y_{t}^{\beta} .
$$

When $\widehat{k}<k_{t}$, then $1>\pi_{t}$ and firms which are monitored use the good technology to produce next period's capital, while firms that are not monitored use the bad technology to produce next period's capital. In this case

$$
k_{t+1}=\left[\pi_{t}+p\left(1-\pi_{t}\right)\right] \omega a y_{t}^{\beta}
$$

Substituting (4.1) into (4.3), and (4.1) (3.12) into (4.4), and defining $\Omega=\omega a \Phi^{\beta}, \quad \Theta=\frac{(1-p)^{2} a \alpha \beta \Phi^{2 \beta-1}}{2}$, the difference equation that describes the accumulation of capital is given by

$$
k_{t+1}=\psi\left(k_{t}\right)
$$

where

$$
\begin{gathered}
\psi\left(k_{t}\right)=\Omega k_{t}^{\beta} \quad \text { if } k_{t} \leq \widehat{k} \\
\psi\left(k_{t}\right)=\Theta k_{t}^{2 \beta-1}+p \Omega k_{t}^{\beta} \quad \text { if } k_{t}>\widehat{k}_{t}
\end{gathered}
$$

In the full monitoring regime when $k_{t} \leq \widehat{k}$ our simple economy behaves like the standard Diamond (1965) model and, given the assumptions in this paper, the stock of capital in period $t+1$ is an increasing and concave function of the stock of capital in period t. In the partial monitoring regime when $k_{t}>\widehat{k}$, instead, we have two possibilities. If $\beta \geq \frac{1}{2}$ then again the economy behaves like the standard Diamond (1965) model and the stock of capital in period 
$\mathrm{t}+1$ is an increasing function of the stock of capital in period t. If instead $\beta<\frac{1}{2}$, initially $\psi\left(k_{t}\right)$ is decreasing ${ }^{9}$ and reaches a minimum for $k_{t}=\left(\frac{\Theta(1-2 \beta)}{p \Omega \beta}\right)^{\frac{1}{1-\beta}}$. It then becomes increasing and turns from convex to concave for $k_{t} \geq\left(\frac{2 \Theta(1-2 \beta)}{p \Omega \beta}\right)^{\frac{1}{1-\beta}}$.

We can now prove:

Lemma 3 When $k_{t+1}=k_{t}$, equation (4.6) defines a unique level of $k_{t}$ which is given by

$$
k_{1}^{*}=\Omega^{\frac{1}{1-\beta}},
$$

and equation (4.7) defines a unique level of $k_{t}$ which is given by

$$
k_{2}^{*}=\left[\frac{2 \Theta}{p \Omega\left[\left(1+\frac{4 \Theta}{p^{2} \Omega^{2}}\right)^{\frac{1}{2}}-1\right]}\right]^{\frac{1}{1-\beta}} \ldots
$$

The fact that in each regime there exists only one possible steady state allows us to limit the number of possible dynamic solutions to our model. Depending on parameters' values we can distinguish among five different cases. ${ }^{10}$

Case 1 (fig.1). The economy reaches a stable steady state in the full monitoring regime. This occurs if the function $\psi\left(k_{t}\right)$ cuts the $45^{\circ}$ line at $k_{1}^{*} \leq \widehat{k}$, i.e. at a level of capital lower than the one at which the economy enters a partial monitoring regime.

Case 2. The economy reaches a stable steady state in the partial monitoring regime. This occurs when $k_{2}^{*}>\widehat{k}$ and either $\beta \geq \frac{1}{2}$ (fig.2a) or $\beta<\frac{1}{2}$ and $k_{2}^{*}>\left(\frac{2 \Theta(1-2 \beta)}{p \Omega \beta}\right)^{\frac{1}{1-\beta}}$ (fig.2b). In both cases

${ }^{9}$ More precisely, the actual shape of the function $\psi\left(k_{t}\right)$ depends on the level of $\widehat{k}$. If $\widehat{k}>\frac{1}{\Phi}\left(\frac{\Theta(1-2 \beta)}{p \Omega \beta}\right)^{\frac{1}{1-\beta}}$, then $\psi\left(k_{t}\right)$ does not have a decreasing part.

${ }^{10}$ These results are rigorously proven in Proposition 1 in the Appendix 
in fact the function $\psi\left(k_{t}\right)$ is increasing and concave in the point at which it cuts the $45^{\circ}$ line and therefore the steady state is stable.

Case 3 (fig.3). There are period-2 cycles and the economy oscillates indefinitely around an unstable steady state. This case occurs when $\beta<\frac{1}{2}, k_{2}^{*}>\widehat{k}, \quad k_{2}^{*} \leq\left(\frac{\Theta(1-2 \beta)}{p \Omega \beta}\right)^{\frac{1}{1-\beta}}$ and $\quad \psi^{\prime}\left(k_{2}^{*}\right)<-1$, i.e. when the function $\psi\left(k_{t}\right)$ cuts the $45^{\circ}$ line in its decreasing, convex part and the slope of the function at that point is lower than or equal to -1 . The interval $\left[\psi^{2}(\widehat{k}), \psi(\widehat{k})\right]$ in fig. 3 represents the trapping region, i.e. the region that the economy enters eventually, and once entered will never leave. If the economy starts with a small $k_{0}$ it will accumulate capital along the "full monitoring" regime, but then it eventually arrives to the point where intermediaries do not monitor all firms and starts bouncing back and forth giving rise to endogenous cycles.

Case 4 (fig.4). The economy oscillates around a stable steady state and eventually converges to it. This case occurs when $\beta<\frac{1}{2}$, $\widehat{k}>k_{2}^{*}, \quad k_{2}^{*} \leq\left(\frac{\Theta(1-2 \beta)}{p \Omega \beta}\right)^{\frac{1}{1-\beta}}$ and $\psi^{\prime}\left(k_{2}^{*}\right)>-1$ i.e. when the function $\psi\left(k_{t}\right)$ cuts the $45^{\circ}$ line in its decreasing, convex part and the slope of the function at that point is greater than -1 .

Case5 (fig.5a e 5b). There are no steady states and the economy cycles between the full monitoring regime and the partial monitoring regime. This occurs when the $45^{\circ}$ line cuts the map $\psi\left(k_{t}\right)$ in the discontinuity. In this case, starting from a small $k_{0}$, the economy accumulates capital along the "full monitoring regime" and then it eventually jumps into the partial monitoring regime. Since in this regime $\psi\left(k_{t}\right)<k_{t}$, the capital stock starts decreasing until the economy goes back to the full monitoring regime. The capital stock therefore cycles between the two regimes and does not converge to any steady state.

These results show that there are many relevant situations, in this simple economy, in which cyclical equilibria appear and capital and output fluctuate. These equilibria appear when the economy enters a partial monitoring regime and intermediaries must decide how many firms to monitor, given the market conditions and the 
cost of monitoring. As we saw before, when interest rates increase the marginal benefit of monitoring rises relatively to its cost and intermediaries increase the amount of resources devoted to monitoring. Since there is an inverse relationship between the level of output and interest rates, when the capital stock increases output increases and the loan interest rates decrease. Intermediaries respond to this decrease in the interest rate by reducing the their monitoring effort. This results in more firms adopting the bad technology. We therefore have two conflicting effects: a higher capital stock increases the stock of capital in the following period because of the positive effect on output, but it also lowers interest rates, thereby reducing monitoring and inducing firms to undertake inferior technologies. If this effect is greater than the first effect, the stock of capital in period $\mathrm{t}+1$ is lower than the stock of capital in period $\mathrm{t}$ and the whole process leading to an increase in the interest rate and to an increase in monitoring starts again i.e. a cycle appears.

\section{Conclusions}

We have analyzed an OLG model where capital producing firms need to borrow from intermediaries in order to finance their production activity but, because of asymmetric information and limited liability, entrepreneurs have the incentive to undertake inefficient investment projects. In order to minimize the consequences of moral hazard, intermediaries undertake a costly monitoring activity. The optimal amount of resources devoted to monitoring turns out to be a function of aggregate economic conditions and, ultimately, of the stock of capital so that the economy may experience cyclical equilibria. When the economy booms, in fact, intermediaries find it optimal to invest fewer resources in monitoring. Projects of lower quality will then be undertaken and the level of capital available in the following period will be lower.

The paper advances the hypothesis that the behavior of intermediaries, in a world of asymmetric information, not only may have a significant impact on the capital stock and on the level of output in the long run but may also be responsible for cyclical behavior. At the same time it emphasizes the important role of intermediaries 
which, in market economies, not only provide funds to firms, but also participate in the selection of investment projects. Episodes of aggregate instability that have occurred both in advanced and emerging economies may actually be the consequence of insufficient monitoring by banks and the consequent investment in low quality projects.

\section{References}

[1] C.Azariadis and B.Smith "Financial Intermediation and Regime Switching in Business Cycles", American Economic Review, 88, 3, 1998, 516-36.

[2] P.Aghion, P.Bacchetta and A.Banerjee "Capital Markets and the Instability of Open Economies", mimeo, November 2000

[3] B.Bernanke and M.Gertler "Agency Costs, Net Worth and Business Fluctuations", American Economic Review 79, 1989, 14-31.

[4] B.Bernanke, M.Gertler and S.Gilchrist "The Financial Accelerator in a Quantitative Business Cycle Framework", NBER Working Paper no.6455, March 1998.

[5] C.Calmstrom and T.S.Fuerst "Agency Costs, Net Worth and Business Fluctuations: a Computable General Equilibrium Analysis", American Economic Review 87, 1997, 893-910.

[6] G.Corsetti, P.Pesenti and N.Roubini, "What Caused the Asian Currency and Financial Crisis?" 1998, NYU, mimeo.

[7] D.Diamond "Financial Intermediation and Delegated Monitoring" Review of Economic Studies, 51,1984, 393-414

[8] J.M.Grandmont, "Periodic and Aperiodic Behavior in Discrete, One-Dimensional, Dynamical Systems", in "Contributions to Mathematical Economics" (W.Hildebrand and A.Mas-Collel, Eds.), North Holland, New York, 1986. 
[9] B.Greenwald and J.E.Stiglitz "Financial Markets Imperfections and Business Cycles" Quarterly Journal of Economics, 108, 1993, 77-114.

[10] C.R.Harvey and A.H.Roper "The Asian Bet" in: "The Crisis in Emerging Financial Markets", (A.Harwood, R.E.Litan and M.Pomerleano Eds.) Brooking Institution Press, 1999.

[11] H. Kaufman "Debt: the Threat to Economic and Financial Stability" Federal Reserve Bank of Kansas Economic Review, December 1986, pp.3-11.

[12] C. P. Kindleberger, "Manias, Panics and Crashes" Macmillan, London

[13] N.Kyotaki and J.Moore, "Credit Cycles" Journal of Political Economy 105, no.2, 1997, 211-48.

[14] H. Minsky, "Can 'it' happen Again? Essays on Instability in Finance", Sharpe, New York, 1982.

[15] OECD "Economic Survey of Korea 1997-98", Paris, 1998, OECD.

[16] M.Pomerleano, "The East Asia Crisis and Corporate Finances the Untold Micro Story". Emerging Markets Quarterly.

[17] P.Romer, "Increasing Returns and Long Run Growth", Journal of Political Economy, 94, 1986, 1002-37.

[18] J.Suarez and O.Sussman, "Endogenous Cycles in a StiglitzWeiss Economy", Journal of Economic Theory 76, 1997, 47-71.

[19] R.M.Townsend "Optimal Contracts and Competitive Markets with Costly State Verification" Journal of Economic Theory,21, 1979, 265-93. 


\section{Appendix}

Proof of Lemma 1. Since a lender will never lend for $x_{t+1}<1$, given (2.1), $\alpha a y_{t}^{\beta}-y_{t} \geq \alpha a y_{t}^{\beta}-x_{t+1} y_{t}$ for any possible $x_{t+1}$. The function $\alpha a y_{t}^{\beta}-y_{t}$ reaches a maximum when $y_{t}=(\alpha a \beta)^{\frac{1}{1-\beta}} \cdot-y_{t}$. Substituting this value of $y_{t}$ in $\alpha a y_{t}^{\beta}-y_{t}$ we obtain $\alpha a(\alpha a \beta)^{\frac{\beta}{1-\beta}}-(\alpha a \beta)^{\frac{1}{1-\beta}}$. If $B>\alpha a(\alpha a \beta)^{\frac{\beta}{1-\beta}}-(\alpha a \beta)^{\frac{1}{1-\beta}}$, therefore, equation (3.1) can never be satisfied for any possible $x_{t+1} \geq 1$.

Proof of Lemma 2. First, notice that if (3.9) is satisfied and $\pi_{t}=0$, then, given $(\mathrm{A} 4), x_{t+1}(1-p)<0$, which cannot be a solution to problem 1. If (3.8) is satisfied, in which case $\pi_{t}=1$ and $x_{t+1}>2$, then, given (2.1) the first order conditions with respect to $y_{t}$ imply (3.11). If (3.7) is satisfied and $1>\pi_{t}>0$, which occurs when $x_{t+1}=2 \pi$, then the first order conditions, given (2.1), imply $\left[\left(\pi_{t}+p\left(1-\pi_{t}\right)\right] \alpha \beta a y_{t}^{\beta-1}-x_{t+1}\left[\pi_{t}+p\left(1-\pi_{t}\right)\right]=0\right.$. Substituting (3.7), we obtain (3.12).

Proof of Lemma 3. Equation (4.8) is obtained by simply setting $k_{t+1}=k_{t}$ in equation (4.6). If we now assume $k_{t+1}=k_{t}=k$ equation (4.7) can be rewritten as $\Theta k^{2(\beta-1)}+p \Omega k^{\beta-1}=1$ which in turn, setting $k^{\beta-1}=z$, can be rewritten as a second degree equation $z^{2}+\frac{p \Omega}{\Theta} z-\frac{1}{\Theta}=0$. This equation admits only one positive root $z=\frac{p \Omega}{2 \Theta}\left[\left(1+\frac{4 \Theta}{p^{2} \Omega^{2}}\right)^{\frac{1}{2}}-1\right]$, which implies equation (4.9).

Proposition 1. i) If $k_{1}^{*} \leq \widehat{k}$, for any $k_{0} \in R_{+}, k_{1}^{*}$ is a unique, stable steady state;

ii) if $k_{1}^{*}>\widehat{k}, k_{2}^{*} \geq \widehat{k}$ and either $\beta \geq \frac{1}{2}$ or $\beta<\frac{1}{2}$ and $k_{2}^{*}>$ $\left(\frac{2 \Theta(1-2 \beta)}{p \Omega \beta}\right)^{\frac{1}{1-\beta}}$, for any $k_{0} \in R_{+}, k_{2}^{*}$ is a unique stable steady state;

iii) if $k_{1}^{*}>\widehat{k}, \beta<\frac{1}{2}, k_{2}^{*} \geq \widehat{k}, k_{2}^{*} \leq\left(\frac{\Theta(1-2 \beta)}{p \Omega \beta}\right)^{\frac{1}{1-\beta}}$ and $\psi^{\prime}\left(k_{2}^{*}\right)<-1$, there are period- 2 cycles and the economy fluctuates for almost all initial conditions, that is for $k_{0} \in R_{+} / D$, where $D$ is at most a 
countable subset of $R_{+}$;

iv) if $k_{1}^{*}>\widehat{k}, \beta<\frac{1}{2}, k_{2}^{*} \geq \widehat{k}$, and $k_{2}^{*} \leq\left(\frac{\Theta(1-2 \beta)}{p \Omega \beta}\right)^{\frac{1}{1-\beta}}$ and $\psi^{\prime}\left(k_{2}^{*}\right)>$ -1 , for any $k_{0} \in R_{+}$, the economy oscillates and converges to a balanced growth path i.e. for any $k_{0} \in R_{+}$, there exists a $t^{\prime}$ such that $\left\{k_{t} ; t \geq t^{\prime}\right\} \subset\{\widehat{k}, \psi(\widehat{k})\}$ and $\lim _{t \rightarrow \infty} k_{t}=k_{2}^{*}$;

v) if $k_{1}^{*}>\widehat{k}, \quad k_{2}^{*}<\widehat{k}$ steady states are non existent and the economy fluctuates for any $k_{0} \in R_{+}$.

Proof. First, observe, as shown in Lemma 2, that in every regime there exists only one level of $k_{t}$ at which $k_{t+1}=k_{t}$ and that the function $\psi\left(k_{t}\right)$ is increasing and concave if $k_{t} \leq \widehat{k}$ or if $\widehat{k}>k_{t}$ and $\beta \geq \frac{1}{2}$. If instead $\widehat{k}>k_{t}$ and $\beta<\frac{1}{2}, \psi\left(k_{t}\right)$ is first decreasing and then increasing, turning from convex to concave. This implies that the function $\psi\left(k_{t}\right)$ will never intersect the $45^{\circ}$ line from below. We can therefore restrict the analysis to cases $\mathrm{i})-\mathrm{v})$.

i) In this case $\psi^{\prime}\left(k_{1}^{*}\right)>0$ and $\psi^{\prime \prime}\left(k_{1}^{*}\right)<0$ and the graphical analysis is sufficient to show that the steady state is unique and stable.

ii) In this case $\psi^{\prime}\left(k_{2}^{*}\right)>0$ and $\psi^{\prime \prime}\left(k_{2}^{*}\right)<0$ and the graphical analysis is sufficient to show that the steady state is unique and stable.

iii) In order to prove the existence of a period-2 cycle is sufficient to show that $\Omega(k)=\psi^{2}(k)-k=0$ has a solution other than $k=k_{2}^{*}$. Since the map $\psi(k)$ intersects the $45^{\circ}$ line only in the point $k_{2}^{*},\left[\psi^{2}(\widehat{k}), \psi(\widehat{k})\right]$ is the trappiing region, $\Omega\left(\psi^{2}(\widehat{k})\right)=\psi^{4}(\widehat{k})-$ $\psi^{2}(\widehat{k}) \geq 0$ and $\Omega(\widehat{k})=\psi^{2}(\widehat{k})-\widehat{k}<0$. Hence, $\Omega(k)=0$ has a solution in $\left[\psi^{2}(\widehat{k}), \psi(\widehat{k})\right]$, which proves the existence of period-2 cycles. Next, suppose that $\psi^{t}\left(k_{0}\right)$ converges. Let the limit point be denoted by $k^{\infty} . k^{\infty}=\psi^{t+1}\left(k_{0}\right)=\psi\left(\lim _{t \rightarrow \infty} \psi^{t}\left(k_{0}\right)\right)=\psi\left(k^{\infty}\right)$, therefore $k^{\infty}=k_{2}^{*}$. Let $D \equiv\left\{k_{0} \in R_{+}\right.$such that $\left.\lim _{t \rightarrow \infty} \psi^{t}\left(k_{0}\right)=k_{2}^{*}\right\}$. Since $k_{2}^{*}$ is locally unstable, $\psi(\widehat{k})$ cannot approach it asymptotically. Hence, $D=\left\{k_{0} \in R_{+}\right.$such that $\psi^{t}\left(k_{0}\right)=k_{2}^{*}$ for a finite $\left.t\right\}$, which is 
at most countable since the shape of $\psi\left(k_{t}\right)$ implies that there is a limited number of $x^{\prime} s$ that solve $k=\psi(x)$. Hence, for almost all initial conditions $k_{t}$ fluctuates indefinitely.

iv) Notice that, for any $k_{0} \in R_{+}$, there exists a $t^{\prime}$ such that $k_{t^{\prime}} \in$ $[\widehat{k}, \psi(\widehat{k})]$. Then, $\widehat{k}<\psi^{2}(\widehat{k})$ implies that $k_{t^{\prime}+1} \in\left[\psi^{2}(\widehat{k}), \psi(\widehat{k})\right] \subset$ $[\widehat{k}, \psi(\widehat{k})]$. Since $0>\psi^{\prime}\left(k_{2}^{*}\right)>-1$, then for $t>t^{\prime}, \psi\left(k_{t}\right)-\psi\left(k_{2}^{*}\right) \rightarrow 0$ as $t \rightarrow \infty$.

v) In this case the $45^{\circ}$ line intersects the function $\psi\left(k_{t}\right)$ in the discontinuity. Since $\psi\left(k_{t}\right)$ is piecewise continuous and the discontinuity is unique, we can partition the real line into the intervals $I_{1}=(0, \widehat{k}], I_{2}=(\widehat{k}, \infty)$. Since there is no $k_{t}$ such that $\psi\left(k_{t}\right)=k_{t}$, for $k_{t} \in I_{1} \psi\left(k_{t}\right)>k_{t}$ and for $k_{t} \in I_{1} \psi\left(k_{t}\right)<k_{t}$. Thus, if $k_{t} \in I_{1}$ the equilibrium sequence is monotonically increasing and there is a $t^{\prime}>0$ such that $k_{t} \in I_{1} \Rightarrow k_{t^{\prime}} \in I_{2}$. When $k_{t} \in I_{2}$, the equilibrium sequence becomes monotonically decreasing and there is an $i>0$ such that $k_{t^{\prime}} \in I_{2} \Rightarrow k_{t^{\prime}+i} \in I_{1}$.

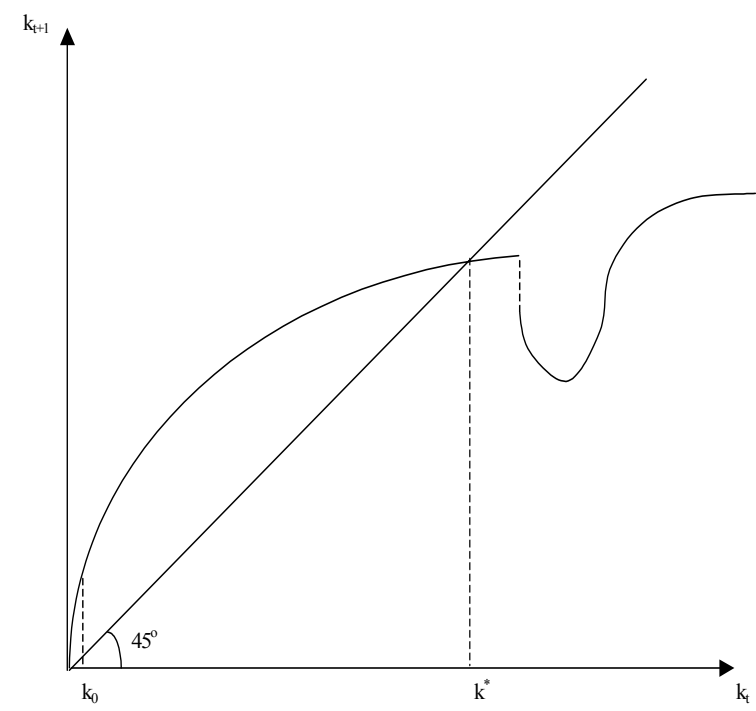

Fig.1

Steady state in the full monitoring regime 


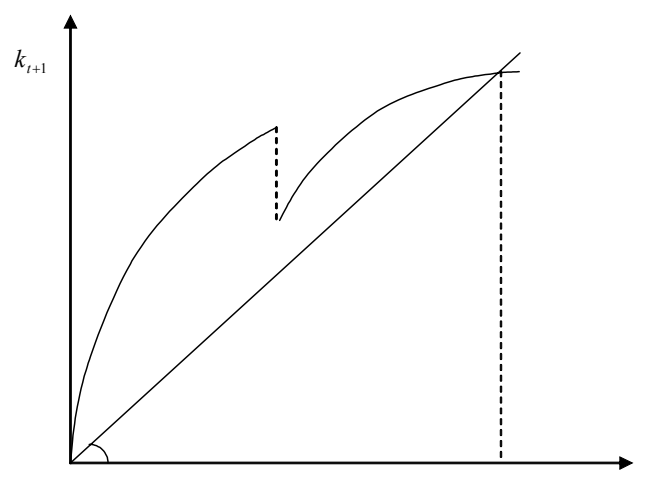

Fig. $2 a$

Steady state in the partial monitoring regime

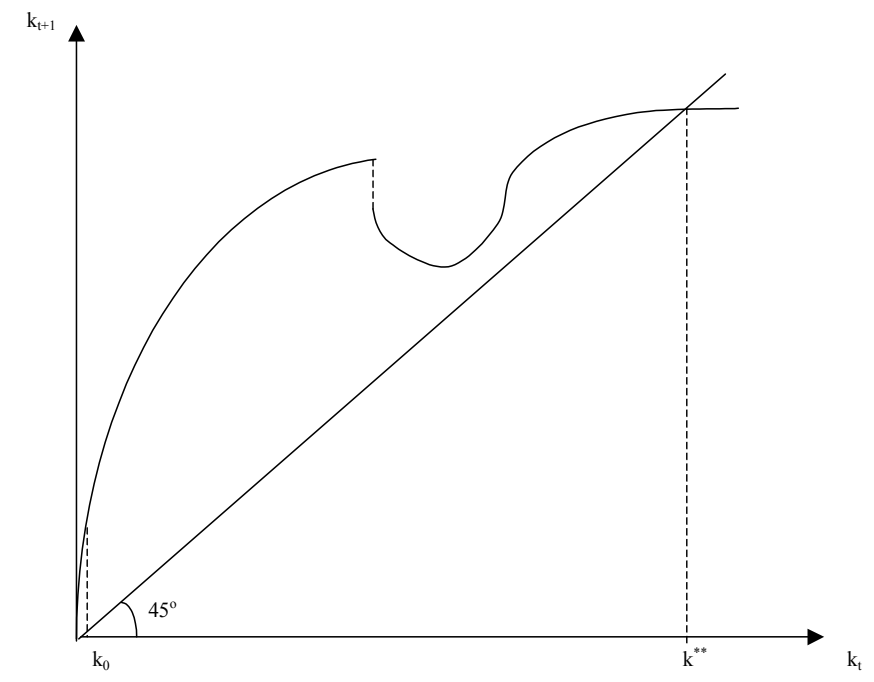

Fig. $2 b$

Steady state in the partial monitoring regime 


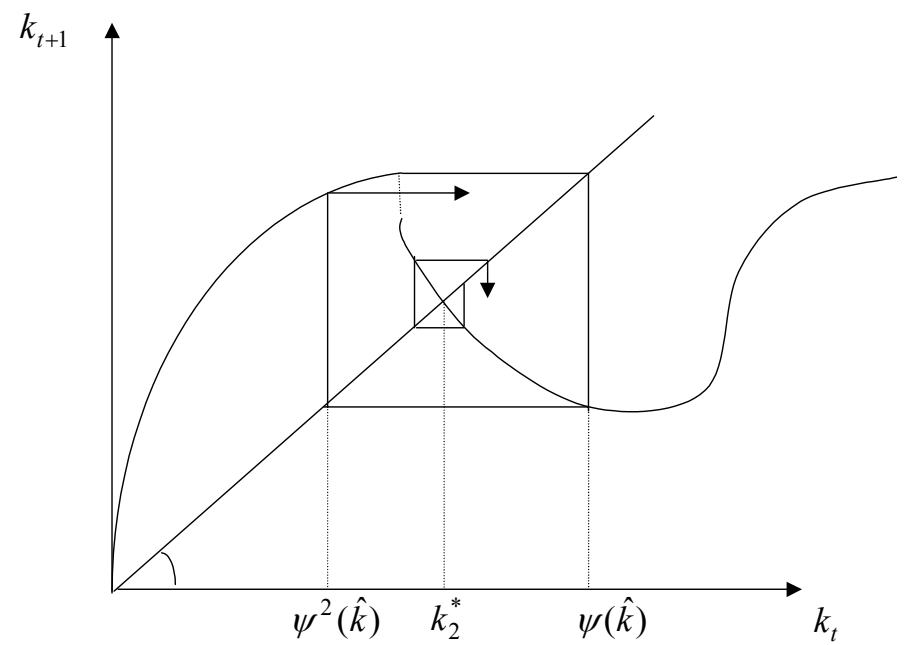

Fig.3

Endogenous cycles around an unstable steady state

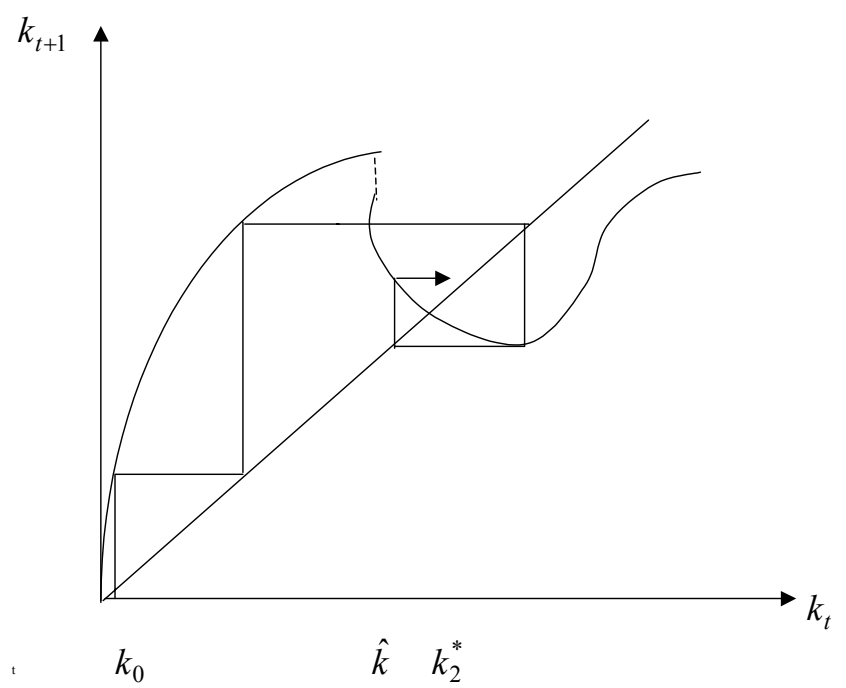

Fig.4

Convergent cycles 


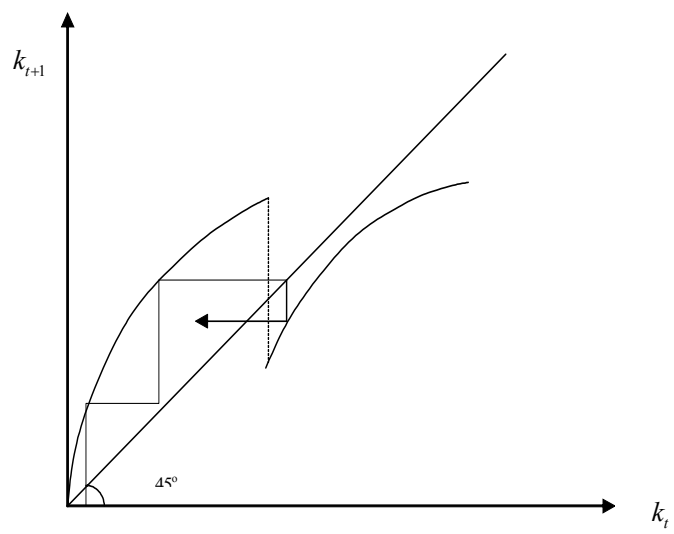

Fig. $5 a$

No steady states. Cycles between the full monitoring regime and the partial monitoring regime

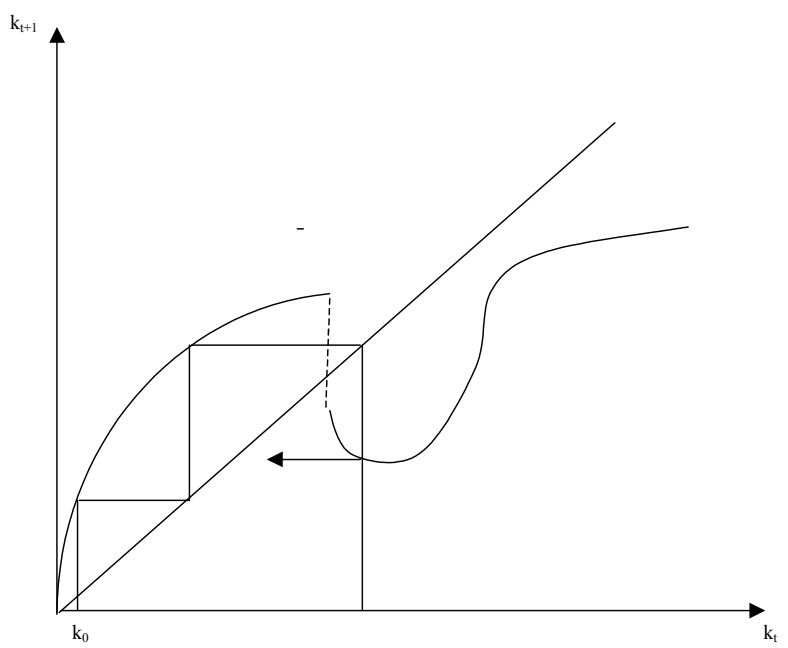

Fig. $5 b$

No steady states. Cycles between the full monitoring regime and the partial monitoring regime 